\title{
A Novel Technique to Maintain Radial Arterial Catheter Position: The Arterial Catheter Stabilizer
}

\author{
Amir Abdel-Kader'1, Nikhil Kaushal'1, Ronak Shah², Michal Gomulka ${ }^{3}$, Tony Wang1, \\ Steven Shulman ${ }^{1}$ \\ ${ }^{1}$ Department of Anesthesiology, Rutgers-New Jersey Medical School, Newark, USA \\ ${ }^{2}$ Department of Anesthesiology, Mt. Sinai School of Medicine, New York, USA \\ ${ }^{3}$ Department of Anesthesiology, New York University School of Medicine, New York, USA \\ Email: steve@steveshulman.com
}

How to cite this paper: Abdel-Kader, A., Kaushal, N., Shah, R., Gomulka, M., Wang, T. and Shulman, S. (2016) A Novel Technique to Maintain Radial Arterial Catheter Position: The Arterial Catheter Stabilizer. Open Journal of Anesthesiology, 6, 193-197. http://dx.doi.org/10.4236/ojanes.2016.61202 $\underline{9}$

Received: July 21, 2016

Accepted: December 26, 2016

Published: December 29, 2016

Copyright $\odot 2016$ by authors and Scientific Research Publishing Inc. This work is licensed under the Creative Commons Attribution International License (CC BY 4.0).

http://creativecommons.org/licenses/by/4.0/

\section{Abstract}

Despite widespread use of arterial catheters, there is remarkably little described about their stabilization in the literature. A brief review of arterial catheterization techniques is included. The fixation techniques described in the literature and in commercial product information are essentially to tape or suture the arterial catheter flat against the skin. Often the wrist is immobilized in the dorsiflexed position to prevent kinking or dislodging of the catheter. We describe a simple device made from a gauze pad and tape to elevate and protect the arterial line while minimizing its kinking during wrist flexion.

\section{Keywords}

Arterial Catheters, Arterial Blood Pressure, Radial Arterial Catheter Position

\section{Introduction}

Arterial blood pressure can be measured directly and indirectly. Direct measurement is invasive and involves placement of an arterial catheter while indirect measurement involves the use of a sphygmomanometer. In the operating room, arterial line access is generally gained via the radial artery. The radial artery is most often used due to ease of accessibility and care, high success rate, and due to the increased collateral circulation to the hand which reduces the likelihood of ischemia in a situation of thrombosis [1] [2] [3]. Radial arterial line stability is important to prevent catheter kinking. During intraoperative motor evoked po- 
tentials, the aggressive flexion of the wrist can lead to kinking or dislodgement of the arterial line. Kinking of the arterial line can lead to occlusion, rendering the arterial line ineffective. Current radial arterial catheter stabilizers (ACS) that are on the market are expensive, over nine dollars per stabilizing unit. This price does not include the arterial line catheter. The novel technique described in this article is much more cost-effective as the material costs fewer than twenty five cents and it takes one to two minutes to construct the arterial stabilizer.

\section{Historical Perspective}

The concept of directly measuring blood pressure was arisen from the mathematician Daniel Bernoulli's work from 1725. Bernoulli was able to use a narrow tube to measure the pressure of fluid in pipes [4]. Stephen Hales was the first person to directly measure arterial blood pressure. In 1733, he was able to successfully measure the direct arterial pressure of horses. In order to accomplish this, he used a nine feet long glass tube and connected it to the horse's carotid and femoral arteries via the trachea of a goose [5] [6]. The technique was modified in 1828 by Jean-Louis Poiseuille. He was able to measure the pressure of the aorta at different points using a U-tube filled with mercury [5] [6] [7]. The first accurate arterial blood pressure reading was recorded by Faivre in 1856 via the femoral artery. He was able to connect a mercury manometer to the artery during an operation [1] [5]. However, despite these efforts, the first clinically useful arterial line was successfully developed and placed in 1949 by Peterson et al. [6].

\section{Various Techniques of Radial Artery Catheter Insertion}

Insertion of a radial artery catheter can be accomplished using the Seldinger technique, the Modified Seldinger technique or the Accelerated Seldinger technique. The Seldinger technique, invented in 1953, involves the use of separate components: a needle, guidewire, dilator, and catheter [8]. After the needle is initially inserted into the radial artery at a $45^{\circ}$ angle with penetration of both the anterior and posterior wall of the artery, the needle is subsequently pulled back into position within the arterial lumen and the guidewire is inserted. Then, catheter is inserted into position. The main complications are hemorrhage and vessel perforation.

The Modified Seldinger technique consists of the above components, except that the needle and catheter come already preassembled and are coupled together. The needle is inserted at an angle as closely parallel to the artery in order to penetrate the anterior wall only, after which the remaining components are threaded as described above [9] [10]. The risks are the same as with the original Seldinger technique.

The Accelerated Seldinger technique (AST) involves a completely preassembled catheter that consists of the above components which are advanced in the manner described for the Seldinger technique [10] [11]. The AST avoids the 
awkward manual exchanges that may lead to contamination and uses a safety mechanism that passively locks the needle safely, hopefully reducing needle stick injuries. In summary, each technique involves manipulation of the radial artery that can lead to vessel damage or its weakening which may increase the chance of catheter failure.

\section{Technique for Using the Arterial Catheter Stabilizer to Provide Radial Arterial Line Stability}

Based on our clinical experience, the authors believe that maintaining the radial arterial catheter at the same angle of insertion reduces the chances of the catheter kinking leading to stasis and thrombosis. In order to accomplish this, a $4 \times 4$ inch piece of gauze is rolled up and held taut at the corners diagonally. Hy-tape ${ }^{\text {tm }}$ adhesive tape is then tightly wrapped around the piece of gauze. This taped gauze is bent into in a horse-shoe shape and placed on the wrist with the opening of the arterial catheter facing proximally and the arterial line resting over the closed end distally. A large Tegaderm ${ }^{\mathrm{tm}}$ Film (Model Number $1626 \mathrm{~W}$ ) $10 \mathrm{~cm}$ by $12 \mathrm{~cm}$ ) is then placed over the arterial catheter stabilizer. This allows for both the radial arterial line to rest at an angle similar to one at which it was initially inserted and easy inspection. In addition, it restricts the movement of the arterial line during flexion of the wrist especially during obtaining motor evoked potentials. The apparatus is shown in Figure 1 and Figure 2. This arterial catheter stabilizer has been successfully used in neurosurgical cases in which motor evoked potentials of the hands were tested without any immobilization of the wrist.

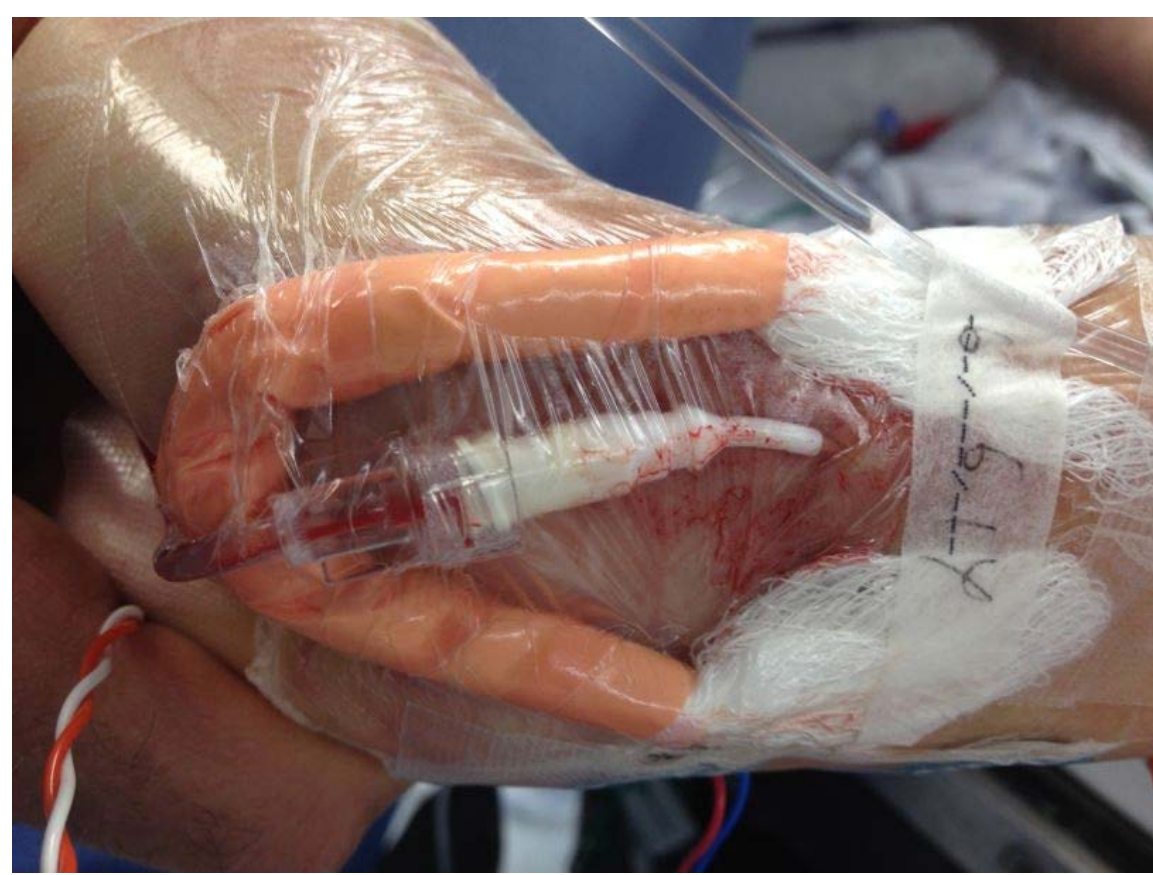

Figure 1. Anterior view shows how the arterial catheter stabilizer secures the arterial catheter and provides easy inspection of the site. 


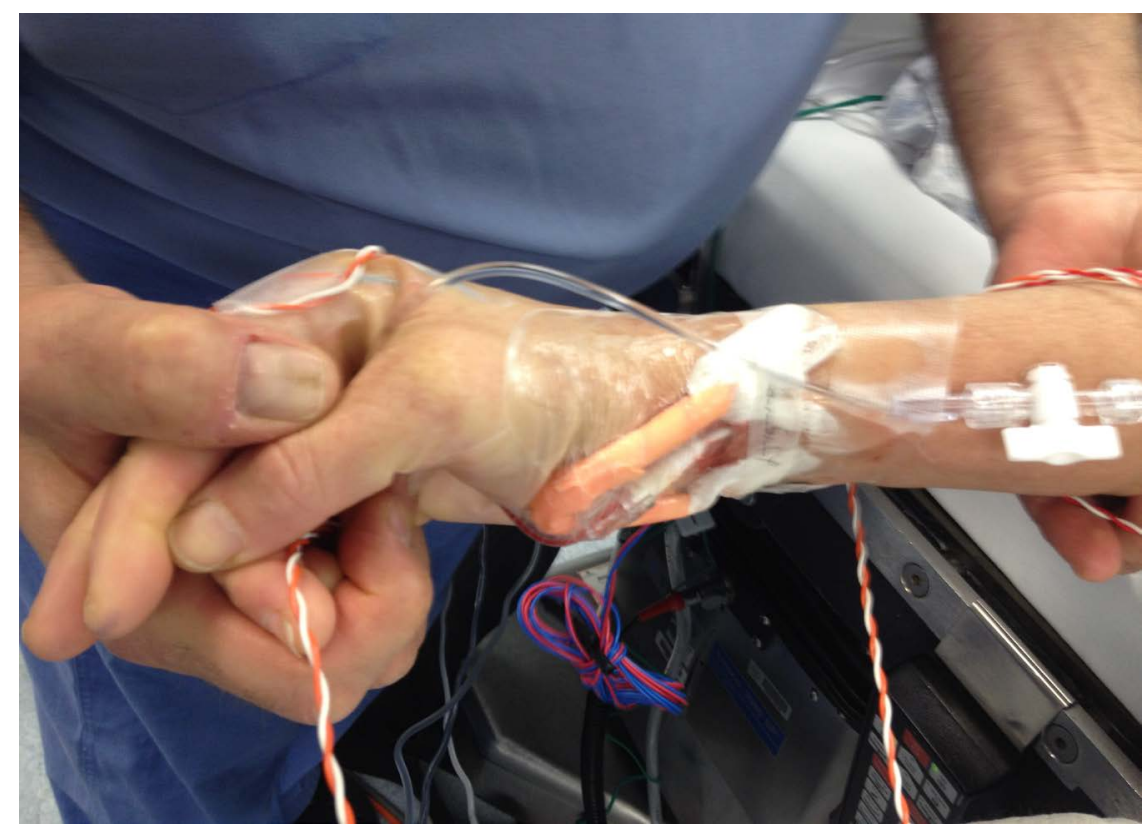

Figure 2. Lateral view shows the arterial catheter stabilizer elevates the arterial catheter away from the wrist so that catheter movement during wrist flexion is minimized. Notice that the catheter stays in an angle closer to the angle of its insertion.

Tips for use of the arterial catheter stabilizer include:

1) Prefabricate the ACS before the procedure. The more it is available, the more it will be used. It is also useful for stabilizing venous catheters especially extremely small ones such as a 24 gauge venous catheter.

2) It is best to rest the connecting tube against the ACS. There is no need to place it between the catheter and the skin.

3) The ACS works best if it placed before placement of the needles for neurophysiological monitoring e.g. motor evoked potentials, electromyographic studies.

4) It is our impression that catheters with the ACS seem less likely to occlude during the procedure and are more likely to be functional that next day. If an arterial catheter is to be used the following day for a second procedure, we strongly suggest that the ACS be used.

5) Upon publication of this article, the authors will place on You-tube ${ }^{\mathrm{Tm}}$ (https://youtu.be/fEAaKlfxBuY) a video showing how to create and use the arterial catheter stabilizer. Please search for "Rutgers arterial catheter stabilizer".

\section{Conclusion}

The arterial catheter stabilizer maintained initial position of the radial arterial line catheter. We believe this is the first report of this kind of device in the literature. Our clinical impression is that the ACS results in catheter survival. This arterial catheter stabilizer is more inexpensive when compared with the radial artery catheter stabilizers that currently exist on the market and can be created 
on an as-needed basis with standard material found in an operating room. In addition, this technique allowed a smaller catheter to be used such as a 22 gauge in patients with peripheral vascular disease whose arteries were unable to be cannulated with a standard 20 gauge catheter. This allowed us to use smaller catheters successfully in patients with peripheral vascular disease who could be difficult to cannulate. While this technique has been used by one author on many occasions, prospective studies are required to prove if it is superior to other ways of arterial catheter stabilization.

\section{References}

[1] Tiru, B., Bloomstone, J.A. and McGee, W.T. (2012) Radial Artery Cannulation: A Review Article. Journal of Anesthesia \& Clinical Research, 3, 209.

[2] Bedford, R.F. (1977) Radial Arterial Function Following Percutaneous Cannulation with 18- and 20-Gauge Catheters. Anesthesiology, 47, 37-39. https://doi.org/10.1097/00000542-197707000-00009

[3] Weiss, B.M. and Gattiker, R.I. (1986) Complications during and Following Radial Artery Cannulation: A Prospective Study. Intensive Care Medicine, 12, 424-428. https://doi.org/10.1007/BF00254675

[4] Quinney, D. (1997) Daniel Bernoulli and the Making of the Fluid Equation. http://plus.maths.org.uk/issue1/bern/index.html

[5] Booth, J. (1977) A Short History of Blood Pressure Measurement. Proceedings of the Royal Society of Medicine, 70, 793-799.

[6] Comroe, J.H. (1977) Retrospectroscope: Insights into Medical Discovery. Von Gehr Press, Menlo Park.

[7] Zuck, D. (1997) Anaesthesia and Physiology: The First Twenty Years. The History of Anaesthesia Society Proceedings, 20, 75-90. http://www.histansoc.org.uk/uploads/9/5/5/2/9552670/volume_20.pdf

[8] Seldinger, S.I. (1953) Catheter Replacement of the Needle in Percutaneous Arteriography: A New Technique. Acta Radiologica, 39, 368-376. https://doi.org/10.3109/00016925309136722

[9] Pancholy, S.B., Sanghvi, K.A. and Patel, T.M. (2012) Radial Artery Access Technique Evaluation Trial: Randomized Comparison of Seldinger versus Modified Seldinger Technique for Arterial Access for Transradial Catheterization. Catheter Cardiovasc Interv, 80, 288-291. https://doi.org/10.1002/ccd.23445

[10] Caparas, J., Hu, J.P. and Hung, H.S. (2014) Does a Novel Method of PICC Insertion Improve Safety? Nursing, 44, 65-67. https://doi.org/10.1097/01.NURSE.0000444725.83265.1d

[11] Smith, B.Y., Bierman, S.F., Pluth, R.A., et al. (2008) Potential Advantages of the Accelerated Seldinger Technique. Poster Presentation at the Association for Vascular Access 22nd Annual Conference, Savannah, Georgia, 11-13 September 2008. https://web.archive.org/web/20110716215924/http://the-wand.com/pdf/LC-0030_A -Poster.pdf 
Submit or recommend next manuscript to SCIRP and we will provide best service for you:

Accepting pre-submission inquiries through Email, Facebook, LinkedIn, Twitter, etc. A wide selection of journals (inclusive of 9 subjects, more than 200 journals)

Providing 24-hour high-quality service

User-friendly online submission system

Fair and swift peer-review system

Efficient typesetting and proofreading procedure

Display of the result of downloads and visits, as well as the number of cited articles Maximum dissemination of your research work

Submit your manuscript at: http://papersubmission.scirp.org/

Or contact ojanes@scirp.org 